\title{
Type 2 diabetes affects bone cells precursors and bone turnover
}

\author{
Francesca Sassi ${ }^{1}$, Ilaria Buondonno ${ }^{1}$, Chiara Luppi ${ }^{1}$, Elena Spertino ${ }^{1}$, Emanuela Stratta ${ }^{1}$, Marco Di Stefano ${ }^{1}$, \\ Marco Ravazzoli', Gianluca Isaia ${ }^{3}$, Marina Trento², Pietro Passera², Massimo Porta², Giovanni Carlo Isaia' \\ and Patrizia D'Amelio ${ }^{1 *}$ (D)
}

\begin{abstract}
Background: Here we study the effect of type 2 diabetes (T2DM) on bone cell precursors, turnover and cytokines involved in the control of bone cell formation and activity.

Methods: We enrolled in the study 21 T2DM women and 21 non diabetic controls matched for age and body mass index (BMI). In each subject we measured bone cell precursors, Receptor Activator of Nuclear Factor $\mathrm{kB}$ (RANKL), Osteoprotegerin (OPG), Sclerostin (SCL) and Dickoppf-1 (DKK-1) as cytokines involved in the control of osteoblast and osteoclast formation and activity, bone density (BMD) and quality trough trabecular bone score (TBS) and bone turnover. T2DM patients and controls were compared for the analyzed variables by one way ANOVA for Gaussian ones and by Mann-Whitney or Kruskal-Wallis test for non-Gaussian variables.

Results: RANKL was decreased and DKK-1 increased in T2DM. Accordingly, patients with T2DM have lower bone turnover compared to controls. BMD and TBS were not significantly different from healthy controls. Bone precursor cells were more immature in T2DM. However the number of osteoclast precursors was increased and that of osteoblasts decreased.

Conclusions: Patients with T2DM have more immature bone cells precursors, with increased number of osteoclasts and decreased osteoblasts, confirming low bone turnover and reduced cytokines such as RANKL and DKK-1. BMD and TBS are not significantly altered in T2DM although, in contrast with other studies, this may be due to the match of patients and controls for BMI rather than age.
\end{abstract}

Keywords: Diabetes, Osteoblast, Osteoclast, Sclerostin, Receptor activator of nuclear factor kB, Bone density

\section{Background}

Type 2 diabetes mellitus (T2DM) increases the risk of fragility fractures [1], even though it is often associated with increased bone density $[1,2]$. T2DM has been associated with poor bone quality [3] and this may lead to increased fracture risk. Nevertheless, how T2DM affects bone is still controversial. Several mechanisms may be involved, such as direct effects of insulin resistance and hyperglycemia on the bone and bone marrow microenvironment, advanced glycation end products of bone matrix proteins, abnormal cytokine production, and impaired neuromuscular/skeletal interactions $[4,5]$. Obesity associated with

\footnotetext{
*Correspondence: patrizia.damelio@unito.it

${ }^{1}$ Department of Medical Science, Gerontology and Bone Metabolic Diseases,

University of Torino, Corso Bramante 88/90, 10126 Torino, Italy

Full list of author information is available at the end of the article
}

T2DM may be a confounder due to its controversial effect on bone per se (see Dolan et al., 2017 for a comprehensive review) [6]. Several studies suggest that obesity protects against bone loss in diabetic patients [7-9]. Moreover, recent data suggest that obesity, regardless of the presence of T2DM, is associated with a favorable bone microarchitecture and greater bone strength at the distal radius and distal tibia [10]. Serum markers of bone formation such as osteocalcin $(\mathrm{OCN})$ and amino-terminal propeptide of procollagen type 1 (P1NP) have been found decreased in T2DM patients [11-13], supporting the hypothesis that bone formation is lower than in controls. Also bone resorption has been found reduced in T2DM by some authors [11, 14], however this data has not been confirmed by others [15]. T2DM may affect bone metabolism influencing osteoblast $(\mathrm{OB})$ and osteoclast $(\mathrm{OC})$ formation and

(c) The Author(s). 2018 Open Access This article is distributed under the terms of the Creative Commons Attribution 4.0 International License (http://creativecommons.org/licenses/by/4.0/), which permits unrestricted use, distribution, and 
activity by altering the cytokines involved in these processes other than having direct toxic effect on bone cells. $\mathrm{OB}$ formation and activity are mainly induced by the activation of the Wnt pathway, two of the most studied inhibitors of this pathway being sclerostin (SCL) and Dickoppf-1 (DKK-1) [16]. Otherwise, osteoclast formation and activity are mainly regulated by the Receptor Activator of Nuclear Factor $\mathrm{kB}$ (RANKL), its receptor (RANK) and its decoy receptor Osteoprotegerin (OPG) [17].

In vitro, in animal models and in humans it has been demonstrated that hyperglycemia increases the level of SCL [18-20] and DKK-1 [21-23], and that these cytokines blunt osteoblast formation and activity. As regards the RANKL/RANK/OPG pathway, this has been studied mainly in relation to cardiovascular damage and vascular calcification in T2DM [24]. Nowadays there are no human data on the relation between the cytokines involved in the control of bone cells and bone cell precursors in patients affected by T2DM. In this paper we show the effect of T2DM on bone turnover, bone precursors cells and cytokines involved in bone turnover taking into account the confounding factor of obesity and age.

\section{Methods}

\section{Study population}

We performed a case-control study enrolling 42 subjects, 21 women affected by T2DM and 21 non diabetic controls. Patients and controls had been in spontaneous menopause for, at least, one year. T2DM patients were matched with controls for Body Mass Index (BMI) \pm 2 SD and age \pm 5 years. Screening for micro-and macrovascular complications of diabetes was done yearly. Retinopathy was investigated by $45^{\circ}$ digital retinal photography and graded according to the American Academy of Ophthalmology Simplified Classification [25]. Nephropathy was screened for by measuring albumin excretion rate and serum creatinine. Neuropathy was assessed according to the San Antonio Consensus [26]. Large vessel disease was screened for by examining peripheral pulses and history of coronary or peripheral artery disease. None of the T2DM patients included were affected by renal or macro-vascular complications, 4 were affected by retinopathy (19\%). Of these patients, 1 was also affected by neuropathy, and another 5 only had neuropathy (23.8\%). (Table 1 shows the clinical characteristics of patients and controls). Five patients (23.8\%) were treated by insulin, 11 by metformin and five by DPP4 inhibitors.

T2DM patients were recruited from the outpatient diabetes clinic of Medicina Interna $1 \mathrm{U}$. In Italy diabetic patients are managed by general practitioners and periodically referred to specialist centers to evaluate their disease state, hence the enrollment of patients from a tertiary referral center did not bias our results. Inclusion criteria for patients were:female genderin post-menopausal period and diagnosis of T2DM.
Table 1 Characteristics of subjects

\begin{tabular}{llll}
\hline & Patients (21) & Controls(21) & $P$ value \\
\hline Age (yrs) & $71 \pm 6$ & $70 \pm 6$ & - \\
Post-menopausalperiod (yrs) & $22 \pm 9$ & $21 \pm 7$ & NS \\
DMduration (yrs) & $16 \pm 2$ & - & - \\
HbA1C (mmol/mol) & $57 \pm 8.1$ & - & - \\
DM complications (\%) & $42.9 \%$ & - & - \\
Retinopathy (\%) & $14.3 \%$ & - & - \\
Neuropathy + retinopathy (\%) & $4.8 \%$ & - & - \\
Neuropathy (\%) & $23.8 \%$ & - & - \\
Insulin treatment (\%) & $23.8 \%$ & & \\
Metformin treatment (\%) & $52.4 \%$ & & \\
DPP4 inhibitors treatment (\%) & $23.8 \%$ & & NS \\
Waist/hip ratio & $0.92(0.88-0.96)$ & $0.88(0.84-0.94)$ & NS \\
Fat mass (\%) & $39.4(36.1-41.1)$ & $39.1(34.1-42.3)$ & NS \\
BMl (Kg/m²) & $29 \pm 5$ & $29 \pm 5$ & - \\
\hline
\end{tabular}

Data depicted are mean \pm SD for Gaussian variables and median with $25^{\circ}$ and $75^{\circ}$ percentiles for non-Gaussian variables, non-continuous variables are shown percentage. Statistical differences were analyzed by using ANOVA one-way or Mann-Whitney $U$ test

Exclusion criteria were: mental inability to sign the informed consent; known secondary osteoporosis; treatment with drugs active on bone turnover within the previous six months including: biphosphonates, strontium ranelate, parathyroid hormone, thyroid hormones, raloxifene, denosumab, corticosteroids, estrogen, oral anticoagulants, calcium and vitamin D andimmunosuppressant (as cyclosporine, azathioprine) within the previous year; diagnosis of type 1 diabetes; use of thiazolidinediones; history of cancer; liver disease, kidney failure (stage II or higher); malabsorption; hyperthyroidism.

Glycemic control in patients was measured by Hemoglobin A1C (HbA1C) with high performance liquid chromatography (HPLC), the mean level was 57 $\pm 8.1 \mathrm{mmol} / \mathrm{mol}$.

Controls were recruited from the general population starting from the database used for our previous study, fully described elsewhere [27]. Briefly, controls were enrolled from the general practitioner lists amongst non-diabetic women without diseases active on bone metabolism, matched for age and BMI to T2DM patients, as previously described. Exclusion criteria were the same used for the patients. The whole population was Caucasian.

\section{Clinical evaluation of bone health}

An accurate medical history, including the presence of fragility fractures, and physical examination was collected in all women. A bone scan was performed with a Hologic QDR 4500 X-ray densitometer to measure bone mineral density (BMD), both at lumbar spine and femur, and to evaluate the presence of vertebral fractures by morphometric DXA analyses. The spinal deformity 
index (SDI) [28] was calculated on DXA morphometry. Bone texture was analyzed by trabecular bone score (TBS) at lumbar vertebrae from DXA images with a dedicated software (TBS iNsight, Medimaps Group SA, Pessac, France). TBS is a textural index that evaluates pixel gray-level variations in the lumbar spine DXA image, providing an indirect index of trabecular microarchitecture. TBS is not a direct physical measurement of bone microarchitecture, but rather an overall score computed by the projection of the 3D structure onto a 2D plane that provides an indirect estimation of bone microarchitecture from spine DXA images [29].

Bone turnover markers, cytokines and bone cells precursors Markers of bone formation, OCN (Life Technologies Corp, Frederick, MD), P1NP (USCN, Life Science Inc. Houston, TX), and of bone resorption serum Tartrate Resistant Acid Phosphatase 5b (TRAP5b, Quidel, San Diego, CA) were measured by ELISA.

RANKL (Biovendor Research and Diagnostic Products, BRNO, Czech Republic), OPG (R\&D Systems Inc., Minneapolis, USA), SCL (R\&D Systems Inc., Minneapolis, USA) and DKK-1 (R\&D Systems Inc., Minneapolis, USA) were also measured by ELISA.

To evaluate the role of circulating $\mathrm{OC}$ and $\mathrm{OB}$ precursors in T2DM, we measured them in peripheral blood mononuclear cells (PBMCs) separated by Ficoll-Paque technique [30]. Briefly, OC precursors were evaluated by staining PBMCs with fluorescein (FITC, supplied by B\&D) conjugated anti-vitronectin receptor (VNR), phycoerythrin (PE, supplied by $\mathrm{B} \& \mathrm{D})$ conjugated anti-CD14 and allophycocyanin (APC, supplied by B\&D) conjugated anti-CD11b $\mathrm{mAb}$, or with the corresponding isotype control, followed by incubation at $4{ }^{\circ} \mathrm{C}$ for $30 \mathrm{~min}$ as previously described [30]. Triple-positive cells (CD14+/CD11b+/VNR+) were regarded as osteoclast precursors, according to the literature [30, 31]. OB precursors were evaluated by staining PBMCs with FITC conjugated anti-CD15 (in order to exclude granulocytes expressing alkaline phosphatase, supplied by e-Bioscience), APC conjugated anti-alkaline phosphatase (ALP, supplied by R\&D System Inc), PE conjugated anti-OCN (supplied by R\&D System Inc), or with the corresponding isotype control, followed by incubation at $4{ }^{\circ} \mathrm{C}$ for $30 \mathrm{~min}$ as previously described [30-32]. $\mathrm{CD} 15-/ \mathrm{ALP}+/ \mathrm{OCN}+$ cells were regarded as osteoblast precursors according to the literature [30-32]. Membrane antigen expression was analyzed with the CellQuest software (Becton Dickinson \& Co).

\section{Fat mass}

In order to compare patients and controls for body fat mass and distribution, body fat was assessed by plicometry (Mahr GMBH Esslingen). The Pollock, Schmidt and Jackson's formula was used on three sites (triceps, subscapular and abdomen) to calculate fat percentage [33]. In order to calculate BMI the women were weighted with a precision scale and their height recorded with a wallmounted altimeter. BMI was measured as weight in $\mathrm{Kg} /$ squared height in meters, to evaluate fat distribution the waist/hip ratio was measured.

\section{Statistical analyses}

The sample size was calculated to provide an $80 \%$ power $(p<0.05)$ to detect a 2 -fold difference in SCL and DKK-1 in T2DM compared to healthy controls. The 2-fold difference was chosen based on previous papers [18-23]. In order to correctly weight the other data obtained the sample calculated post-hoc to evaluate differences in BMD to provide an $80 \%$ power $(p<0.05)$ to detect a $0.140 \mathrm{~g}$ difference in BMD in T2DM compared to healthy controls48 patients per group will be necessary. The $0.140 \mathrm{~g}$ difference was chosen based on previous papers $[1,2]$. The sample size needed to evaluate differences in TBS to provide an $80 \%$ power $(p<0.05)$ to detect a 0.05 difference in TBS in T2DM compared to healthy controls 100 patients per group will be necessary. The 0.05 difference was chosen on the basis of a previous paper [34]. The sample size needed to evaluate differences in bone turnover and in particular in P1NP to provide an $80 \%$ power $(p<0.05)$ to detect a $8 \mathrm{ng} / \mathrm{mL}$ difference in T2DM compared to healthy controls $33 \mathrm{pa}-$ tients per group will be necessary. The $8 \mathrm{ng} / \mathrm{mL}$ difference was chosen on the basis of previous paper [35].

T2DM patients and controls were compared by one-way ANOVA for Gaussian variables, by Mann-Whitney or Kruskal-Wallis test for non-Gaussian variables. Gaussian distribution was evaluated by kurtosis test. Gaussian variables were correlated by Pearson's coefficient, nonGaussian with Spearman correlation. Data were tested for outliers with the ROUT method, no outliers were identify and removed from the analyses. Statistics were performed by means of SPSS 24.0 for windows, Graph Pad Prism 7.0 for windows was used to drawn the graphs. $P$ values were considered significant if lower than 0.05 .

\section{Results \\ T2DM affects bone precursors cell}

To evaluate if T2DM affects circulating bone precursors cells, we measured circulating $\mathrm{OB}$ and $\mathrm{OC}$ precursor cells and cytokines involved in osteoclastogenesis, osteoblastogenesis and in the regulation of bone turnover. We observed a significant reduction of circulating $\mathrm{OB}$ precursors cells in T2DM patients compared to controls (Fig. 1a), whereas OC precursors are increased (Fig. 1c). Both $\mathrm{OC}$ and $\mathrm{OB}$ precursors are more immature in diabetic patients; in particular OBs express lower levels of ALP and OCs express lower levels of VNR (Fig. 1b, d). 

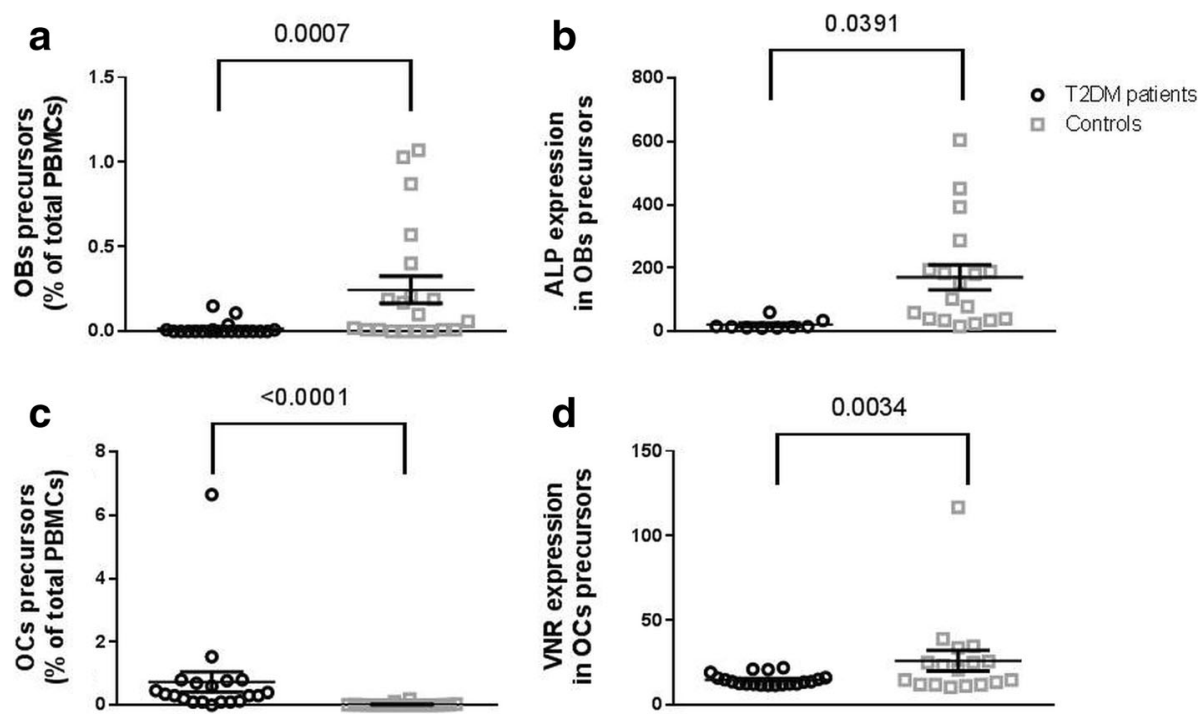

Fig. 1 Dot plots show bone cell precursors in peripheral blood in T2DM patients and controls. Panel a: OB precursor cells; Panel b: ALP expression by OB precursor cells as measured by flow cytometry; Panel $\mathbf{c}$ : OC precursor cells; Panel $\mathbf{d}$ : VNR expression by OC precursor cells as measured by flow cytometry. $P$ value was calculated with by one way ANOVA and is shown in the graph when significant

Cytokines involved in the regulation of bone cells are altered in T2DM patients: DKK-1 was increased in patients compared to controls $(p=0.04)$, whereas RANKL was decreased in T2DM $(p=0.0362)$. DKK-1 was $1824 \mathrm{pg} /$ $\mathrm{mL}$ (1345-2572 interquartile range (IQR)) in T2DM versus $1526 \mathrm{pg} / \mathrm{mL}$ (963.2-1792 IQR) in the control group; RANKL was $3590 \mathrm{pg} / \mathrm{mL}$ (1434-7154 IQR) in T2DM versus $5018 \mathrm{pg} / \mathrm{mL}$ (2632-9343 IQR) in the control group (Fig. 2a, c). OPG was not significantly altered $965.2 \mathrm{pg} / \mathrm{mL}$ (759.1-1346IQR) in T2DM versus $938 \mathrm{pg} / \mathrm{mL}$ (783-1207
IQR) in the control group (Fig. 2b). SCL was undetectable in the majority of both patients' and controls' sera $561.3 \pm$ $73.4 \mathrm{pg} / \mathrm{mL}$ in T2DM versus $309.8 \pm 31 \mathrm{pg} / \mathrm{mL}$ (Fig. 2d). In three T2DM and 5 controls SCL was detectable in the serum, in those subjects bone formation measured by P1NP was significantly lower $(12,420.6 \pm 6706.1$ vs $24,025.2$ $\pm 992.9, p=0.003$ ), no other differences in the tested variables were detectable. The increased level of SCL may be related to decreased bone formation measured by P1NP.
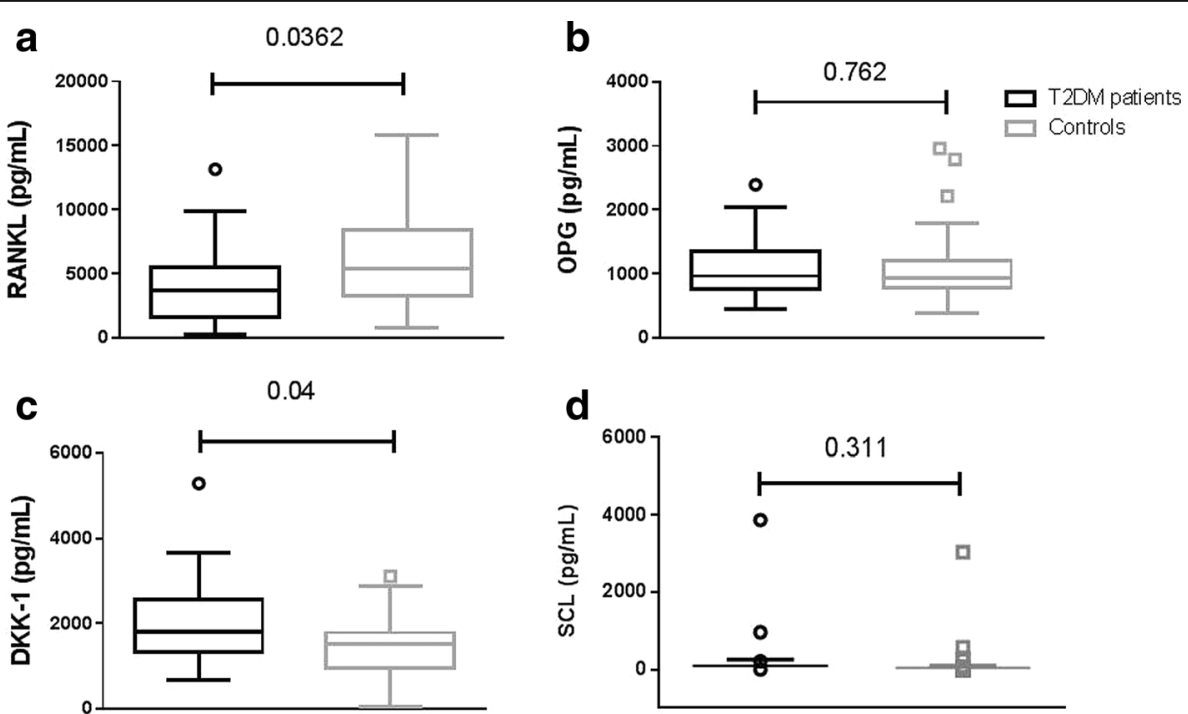

Fig. 2 Graphs show cytokines involved in the control of bone cells formation and activity in T2DM patients and controls. Panel a: RANKL; Panel b: OPG; Panel c: DKK-1. Panel d: SCL. Box and whiskers plot displays median, the first and third quartiles, and the minimum and maximum of the data. $P$ value was calculated with by Mann-Whitney test and is shown in the graph when significant 
Age per se is weakly correlated with RANKL $(R=0.32$, $p=0.047)$ and with $\mathrm{OB}$ precursors maturation $(R=-$ $0.384, p=0.048)$. Post-menopausal state is directly correlated with RANKL $(R=0.323, P=0.045)$. Other parameters are not influenced by age, post-menopausal state or by BMI.

Glycemic control measured by HbA1C did not correlate with bone cell precursor percentage and maturation, nor with cytokines involved in the control of bone turnover. There were no significant differences in the parameters analyzed in patients with or without diabetic complications and between patients taking different anti-hyperglycaemic drugs (data not shown).

\section{Bone metabolism is impaired in T2DM patients}

BMD measured at lumbar spine, femoral neck and total femur was not significantly different between patients and controls; even though lumbar BMD was, on average, higher in T2DM than in controls. Bone structure measured by TBS, as well as SDI, were not altered in diabetic patients compared to controls (Table 2).

Obesity influences bone per se as there were significant correlations between BMI, BMD and TBS, the distribution of fat influenced only TBS (Table 3). Bone formation measured by P1NP as well as bone resorption measured by TRAP5b were significantly decreased in T2DM (Fig. 3). Glycemic control measured by HbA1C influenced bone structure but not bone density (Table 3). As regards bone turnover markers, HbA1C was inversely correlated with bone formation measured by OCN $(R=-$ $0.59, p=0.005)$.

\section{Discussion}

The detrimental effect of T2DM on bone is well established $[1,2]$, but the possible mechanisms through which this happens have not been clearly elucidated. Here we evaluated the effect of T2DM on bone precursor cells and cytokines in patients and controls matched for BMI as well as age. One of the most confounding factor in the evaluation of diabetes effect on bone health is obesity, which is often associated with T2DM and has controversial effect on bone metabolism and fracture risk per se. Some studies suggest that obese subjects have a lower risk of proximal femur and vertebral fracture

Table 2 Bone health in T2DM patients and controls

\begin{tabular}{llll}
\hline & T2DM patients (21) & Controls (21) & $P$ value \\
\hline Lumbar BMD (g/cm2) & $0.97 \pm 0.16$ & $0.92 \pm 0.15$ & 0.059 \\
FemoralBMD (g/cm2) & $0.71 \pm 0.12$ & $0.69 \pm 0.11$ & 0.275 \\
SDI & $0(0-1)$ & $0(0-1)$ & 0.982 \\
TBS & $0.926(0.799-1.027)$ & $0.965(0.766-1.051)$ & 0.875 \\
\hline
\end{tabular}

Data depicted are mean \pm SD for Gaussian variables and median with $25^{\circ}$ and $75^{\circ}$ percentiles for non-Gaussian variables. Statistical differences are analyzed by using ANOVA one-way or Mann-Whitney $\mathrm{U}$ test
Table 3 Correlations between bone density and structure, obesity and glycemic control

\begin{tabular}{llllll}
\hline & & $\mathrm{BMl}$ & Fat mass & Waist/hip & $\mathrm{HbA1C}$ \\
\hline Lumbar BMD & $\mathrm{r}$ & $\mathbf{0 . 2 3}$ & 0.84 & 0.91 & -0.35 \\
& $\mathrm{p}$ & $\mathbf{0 . 0 0 5}$ & 0.338 & 0.276 & 0.286 \\
Femoral BMD & $\mathrm{r}$ & $\mathbf{0 . 2 7}$ & 0.154 & 0.10 & -0.092 \\
& $\mathrm{p}$ & $\mathbf{0 . 0 0 1}$ & 0.078 & 0.904 & 0.701 \\
TBS & $\mathrm{r}$ & $\mathbf{- 0 . 3 1 9}$ & -0.36 & $\mathbf{- 0 . 3 4}$ & $\mathbf{- 0 . 5 5}$ \\
& $\mathrm{p}$ & $<\mathbf{0 . 0 0 0 1}$ & 0.693 & $<\mathbf{0 . 0 0 0 1}$ & $\mathbf{0 . 0 1 6}$
\end{tabular}

Pearson' coefficient correlations between BMD measured at lumbar spine and at femoral neck and BMI, Fat mass $\%$ and waist/hip ratio in the whole population under study, TBS was correlated by Spearman coefficient. Correlations between bone parameters and $\mathrm{HbA1C}$ were run only in T2DM patients. Significant values are in bold

compared to adults with normal BMI [36, 37]. However the risk of fracture in obese subjects is variable at different skeletal sites according to the difference in falling mechanisms in these patients; in particular the risk for proximal humerus, upper leg and ankle fracture is higher in obese than in non-obese adults [38]. Moreover, increased fat mass could be detrimental to bone due to increased inflammation and production of adipokines that affect bone turnover [39, 40]. For these reasons, we enclosed in this study controls matched with patients for BMI as well as for age. The use of obese controls may explain why, differently from other studies, we did not find significant differences in bone microarchitecture measured by TBS between T2DM patients and controls. Although our study was not powered to measure differences in TBS $[3,41]$, our data show that obesity is inversely correlated with bone quality measured by TBS.

Here we show that osteoblast precursors cells are decreased and more immature according with decreased bone formation and increased DKK-1, whereas OC precursors are increased in the peripheral blood of T2DM patients. Data on OCs seem to be in contrast with decreased bone resorption in patients. However, it should be underlined that these are immature cells, which may not be able to home in bone microenvironment. Low RANKL levels in patients may explain the low grade of OCs maturation and decreased bone resorption.

This is the first study to evaluate bone cell precursors in the peripheral blood of diabetic patients.Previous data ina diabetic mouse model suggested reduced osteoclast and osteoblast formation in bone microenvironment [42]. An elegant in vitro study suggests that osteoclastogenesis mediated by RANKL is impaired in the presence of high glucose levels [43].

The increase in DKK-1, a well-known negative regulator of bone formation, may explain the decrease in bone formation in T2DM and confirms previous reports [18-20]. On the contrary, SCL was mostly undetectablein our cohort of patients. In the patients with detectable level 

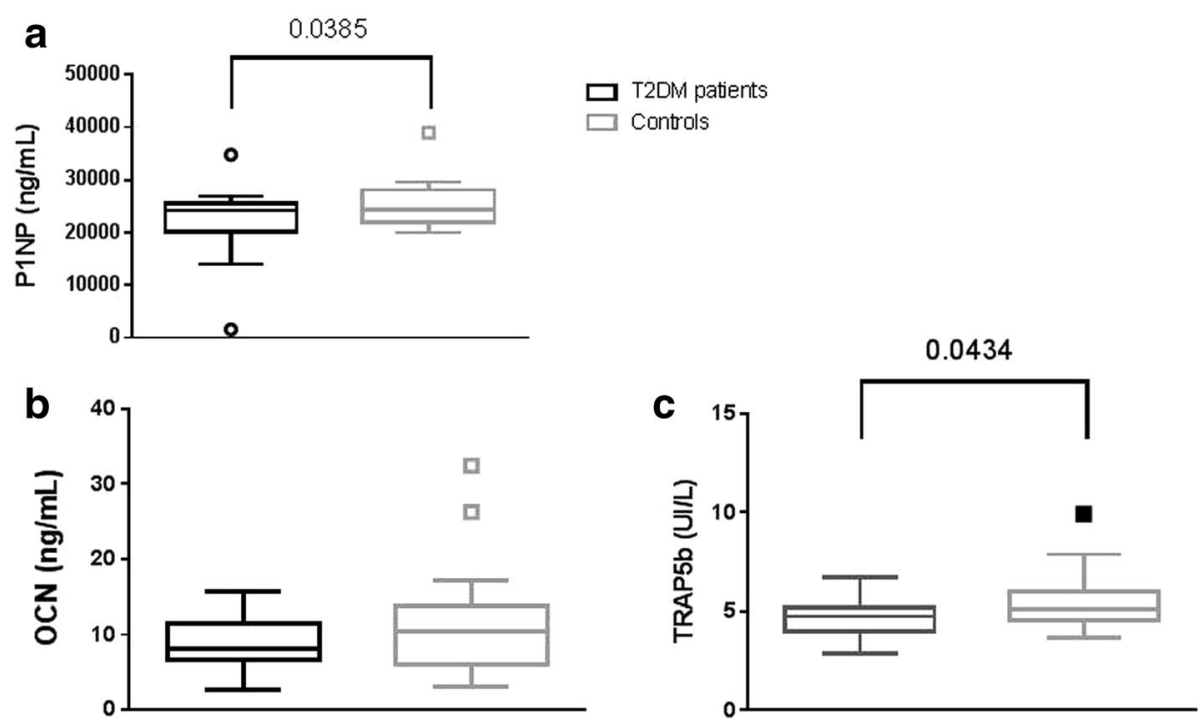

Fig. 3 Graphs show bone turnover markers in T2DM patients and controls. Panel a: the bone formation marker P1NP; Panel b: the bone formation marker OCN; Panel $\mathbf{c}$ : the bone resorption marker TRAP5b. Box and whiskers plot displays median, the first and third quartiles, and the minimum and maximum of the data. P value was calculated with by Mann-Whitney test and is shown in the graph when significant

we found a decreased bone formation without any other differences in the variables measured. Several studies investigated the levels of SCL in diabetic patients reporting conflicting results. Gennari et al. [44] showed increased levels of SCL in T2DM, but not in Type 1 diabetes mellitus (T1DM); other studies reported increased SCL in T2DM [45-47]. A recent study on post-menopausal women showed no difference between diabetic and non-diabetic patients in SCL levels [48]. In our study we evaluated only post-menopausal obese subjects, and this may be the reason why we achieved different results from other studies which included younger, leaner populations, also including men. Glycemic control, the use of different anti-hyperglycaemic drugs and the presence of diabetic complications did not appear to bias our results. Poor glycemic control may influence the levels and activity of cytokines active on bone turnover, some studies demonstrated that OPG is increased in T2DM and T1DM patients regardless to their glycemic control $[49,50]$, this finding is controversial as another study shows a reduction in OPG in T1DM patients [51], here we do not find any significant increase in OPG regardless to glycemic control. RANKL levels seem not to be influenced by glycemic control as shown by Lappin and colleagues [49], we found a decreased RANKL level without any correlation with glycemic control. SCL levels were not studied in relation with glycemic controls in previous studies $[20,44]$ here we do not find any relationship between glycemic control and SCL.

As regards clinical evaluation of bone health, we did not find a significant increase in BMD in T2DM compared to controls, in contrast to previous results [1, 2]. However, our cohort was small and the use of obese controls may have influenced this result as BMI per se, regardless of T2DM, is directly correlated with BMD both at lumbar spine and femoral neck.

As regards bone turnover, we found a significant decrease in bone formation and bone resorption in T2DM, confirming other studies $[22,35,52]$.

The study was not powered to detect differences in fracture prevalence, hence the similar SDI between T2DM and controls may be due to chance. Age was weakly correlated with RANKL, as expected, and interestingly - inversely correlated with $\mathrm{OB}$ precursor maturation. Use of controls matched with patients for age and BMI excludes this as a confounding factor.

Our study has several strengths and limitations. The analyses of bone turnover and related controlling cytokines was performed in well-characterized cohorts of patients and matched controls. This is the first study evaluating the role of bone cell precursors in T2DM. The significance of our findings may be limited by the small sample size and lack of measurement of parameters related to inflammation and adipocytokines production, some of the results reported may be flawed by the insufficient power.

\section{Conclusion}

We show that bone precursor cells are affected by T2DM and, in particular there was a reduction of $\mathrm{OB}$ precursors and an increase in OC precursors. Both cell types appear to be more immature in T2DM, and this could be explained by increased levels of DKK-1 and decreased levels of RANKL. 


\section{Abbreviations}

ALP: Alkaline Phosphatase; APC: Allophycocyanin; BMD: Bone Mineral Dansity; BMI: Body Mass Index; DKK-1: Dickkopf-related Protein 1; FITC: Fluorescein Isothiocyanate; HbA1C: Hemoglobin A1C; HPLC: High Performance Liquid Chromatography; IQR: Interquartile Range; OB: Osteoblast; OC: Osteoclast; OCN: Osteocalcin; OPG: Osteoprotegerin; P1NP: Procollagen Type 1 Amino-terminal Propeptide; PBMCs: Peripheral Blood Mononuclear Cells; PE: Phycoerythrin; RANK: Receptor Activator of Nuclear Factor Kappa-B; RANKL: Receptor Activator of Nuclear Factor Kappa-B Ligand; SCL: Sclerostin; SDI: Spinal Deformity Index; T1DM: Type 1 diabetes mellitus; T2DM: Type 2 diabetes mellitus; TBS: Trabecular Bone Score; TRAP5b: Tartrate-resistant Acid Phosphatase 5b; VNR: Vitronectin

\section{Funding}

This work has been founded by Italian Ministry for University and Research. FS is supported by a grant from MIUR PRIN 2015.

IB is supported by a grant from ERC CONSOLIDATOR GRANT -European Project "BOOST".

\section{Availability of data and materials}

The datasets generated and/or analysed during the current study are not publicly available but are available from the corresponding author on reasonable request.

\section{Authors' contributions}

FS, MR and IB performed the lab experiments, acquired and analyzed the lab data. FS and IB partecipated in drafting and critically revising the manuscript. CL, ESpertino, EStratta, MDS, MR, Gl, MT and PP performed the clinical evaluation of patients and managed the data set. MP and GCl participated in the study design and were major contributors in writing the manuscript. PD designed the study,performed the statistical analyses and wrote the paper. All authors read and approved the final manuscript.

\section{Ethics approval and consent to participate}

The study was approved by the Ethics Committee of our Hospital ("Comitato Etico Interaziendale A.O.U. Città della Salute e della Scienza di Torino - A.O. Ordine Mauriziano - A.S.L. TO1"), in accordance with the ethical standards of the Declaration of Helsinki and its later amendments. Informed consent was obtained from all individual participants included in the study.

\section{Consent for publication}

Not applicable.

\section{Competing interests}

The authors declare that they have no competing interests.

\section{Publisher's Note}

Springer Nature remains neutral with regard to jurisdictional claims in published maps and institutional affiliations.

\section{Author details}

'Department of Medical Science, Gerontology and Bone Metabolic Diseases, University of Torino, Corso Bramante 88/90, 10126 Torino, Italy. ${ }^{2}$ Department of Medical Science, Internal Medicine, University of Torino, Torino, Italy. ${ }^{3}$ Geriatric Division, University of Turin, San Luigi Gonzaga Hospital, Orbassano, Turin, Italy.

Received: 26 February 2018 Accepted: 1 August 2018 Published online: 08 August 2018

\section{References}

1. Janghorbani M, Van Dam RM, Willett WC, Hu FB. Systematic review of type 1 and type 2 diabetes mellitus and risk of fracture. Am J Epidemiol. 2007; 166:495-505.

2. Bonds DE, Larson JC, Schwartz AV, et al. Risk of fracture in women with type 2 diabetes: the Women's health initiative observational study. J Clin Endocrinol Metab. 2006;91:3404-41.

3. Dhaliwal R, Cibula D, Ghosh C, Weinstock RS, Moses AM. Bone quality assessment in type 2 diabetes mellitus. Osteoporos Int. 2014;25:1969-73.

4. Starup-Linde J, Vestergaard P. Management of endocrine disease: diabetes and osteoporosis: cause for concern? Eur J Endocrinol. 2015;173:R93-9.
5. Xu F, Dong Y, Huang $X$, et al. Decreased osteoclastogenesis, osteoblastogenesis and low bone mass in a mouse model of type 2 diabetes. Mol Med Rep. 2014 10:1935-41.

6. Dolan E, Swinton PA, Sale C, Healy A, O'Reilly J. Influence of adipose tissue mass on bone mass in an overweight or obese population: systematic review and meta-analysis. Nutr Rev. 2017; https://doi.org/10.1093/nutrit/ nux046.

7. Bridges MJ, Moochhala SH, Barbour J, Kelly CA. Influence of diabetes on peripheral bone mineral density in men: a controlled study. Acta Diabetol. 2005;42:82-6.

8. Wakasugi M, Wakao R, TawataM,Gan N, Koizumi K,Onaya T Bone mineral density measured by dual energy $\mathrm{x}$-ray absorptiometry in patients with non-insulin-dependent diabetes mellitus Bone1993;14:29-33.

9. Perez-Castrillon JL, De Luis D, Martin-EscuderoJC,Asensio T, del Amo R, Izaola O. Non-insulin-dependent diabetes, bone mineral density, and cardiovascular risk factors. J Diabetes Complicat 2004;18:317-321.

10. Evans AL, Paggiosi MA, Eastell $R$, Walsh JS. Bone density, microstructure and strength in obese and normal weight men and women in younger and older adulthood. J Bone Miner Res. 2015;30:920-8.

11. Rubin MR. Bone cells and bone turnover in diabetes mellitus. Curr Osteoporos Rep. 2015; https://doi.org/10.1007/s11914-015-0265-0.

12. Rosen CJ, Chesnut CH, Mallinak NJ. The predictive value of biochemical markers of bone turnover for bone mineral density in early postmenopausal women treated with hormone replacement or calcium supplementation. J Clin Endocrinol Metab. 1997; https://doi.org/10.1210/jcem.82.6.4004.

13. Shu A, Yin MT, Stein E, et al. Bone structure and turnover in type 2 diabetes mellitus. Osteoporos Int. 2012; https://doi.org/10.1007/s00198-011-1595-0.

14. Oz SG, Guven GS, Kilicarslan A, Calik N, Beyazit Y, Sozen T. Evaluation of bone metabolism and bone mass in patients with type-2 diabetes mellitus. J Natl Med Assoc. 2006:98:1598-604.

15. Achemlal $L$, Tellal $S$, Rkiouak $F$, et al. Bone metabolism in male patients with type 2 diabetes. Clin Rheumatol. 2005; https:/doi.org/10.1007/s10067-004-1070-9.

16. Wang Y, Li YP, Paulson C, et al. Wnt and the Wnt signaling pathway in bone development and disease. In: Landmark Ed.Front Biosci; 2014. p. 379-407

17. Oikawa T, Kuroda Y, Matsuo K. Regulation of osteoclasts by membranederived lipid mediators. Cell Mol Life Sci. 2013:70:3341-53.

18. Hie M, litsuka N, Otsuka T, et al. Insulin-dependent diabetes mellitus decreases osteoblastogenesis associated with the inhibition of Wnt signaling through increased expression of Sost and Dkk1 and inhibition of Akt activation. Int J Mol Med. 2011:28:455-62

19. Gaudio A, Privitera F, Battaglia K, et al. Sclerostin levels associated with inhibition of the Wnt/ $\beta$-catenin signaling and reduced bone turnover in type 2 diabetes mellitus. J Clin Endocrinol Metab. 2012;97:3744-50.

20. García-Martín A, Rozas-MorenoP, Reyes-García R, et al. Circulating levels of sclerostin are increased in patients with type 2 diabetes mellitus. J Clin Endocrinol Metab. 2012;97:234-41.

21. Lin $C L$, Wang JY, Ko JY, Huang YT, Kuo YH, Wang FS. Dickkopf-1 promotes hyperglycemia-induced accumulation of mesangial matrix and renal dysfunction. J Am Soc Nephrol. 2010;21:124-35.

22. Garcia-Martín A, Reyes-Garcia R, García-Fontana B, et al. Relationship of Dickkopf1 (DKK1) with cardiovascular disease and bone metabolism in caucasian type 2 diabetes mellitus. PLoS One. 2014;9:e111703.

23. Gaudio A, Privitera F, Pulvirenti I, Canzonieri E, Rapisarda R, Fiore CE. The relationship between inhibitors of the Wntsignalling pathway (sclerostin and Dickkopf-1) and carotid intima-media thickness in postmenopausal women with type 2 diabetes mellitus. DiabVasc Dis Res. 2014;11:48-52.

24. Ndip A, Williams A, Jude EB, et al. The RANKL/RANK/OPG signaling pathway mediates medial arterial calcification in diabetic Charcot neuroarthropathy. Diabetes. 2011;60:2187-96

25. Wilkinson CP, Ferris FL 3rd, Klein RE, et al. (Global Diabetic Retinopathy Project Group). Proposed international clinical diabetic retinopathy and diabetic macular edema disease severity scales. Ophthalmology. 2003; https://doi.org/10.1016/S0161-6420(03)00475-5

26. Consensus statement: Report and recommendations of the San Antonio conference on diabetic neuropathy. American Diabetes Association American Academy of Neurology. Diabetes Care. 1988;11:592-7.

27. D'Amelio P, Spertino E, Martino F, Isaia GC. Prevalence of postmenopausal osteoporosis in Italy and validation of decision rules for referring women for bone densitometry. Calcif Tissue Int. 2013;92:437-43.

28. Kerkeni S, Kolta S, Fechtenbaum J, Roux C. Spinal deformity index (SDI) is a good predictor of incident vertebral fractures. Osteoporos Int. 2009;20:1547-52. 
29. Silva BC, Leslie WD, Resch $H$, et al. Trabecular bone score: a noninvasive analytical method based upon the DXA image. Bone Miner Res. 2014;29: 518-30

30. D'Amelio P, Cristofaro MA, Grimaldi A, et al. The role of circulating bone cell precursors in fracture healing. Calcif Tissue Int. 2010;86:463-9.

31. Eghbali-Fatourechi GZ, Lamsam J, Fraser D, Nagel D, Riggs BL, Khosla S. Circulating osteoblast-lineage cells in humans. N Engl J Med. 2005;352: 1959-66.

32. D'Amelio P, Tamone C, Sassi F, et al. Teriparatide increases the maturation of circulating osteoblast precursors. Osteoporos Int. 2012;23:1245-53.

33. Jackson AS, Pollock ML, Ward A. Generalized equations for predicting body density of women. Med Sci Sports Exerc. 1980;12:175-81.

34. Choi YJ, Ock SY, Chung YS. Trabecular bone score (TBS) and TBS-adjusted fracture risk assessment tool are potential supplementary tools for the discrimination of morphometric vertebral fractures in postmenopausal women with type 2 diabetes. J Clin Densitom. 2016; https://doi.org/10. 1016/j.jocd.2016.04.001.

35. Purnamasari D, Puspitasari MD, Setiyohadi B, Nugroho P, Isbagio $H$. Low bone turnover in premenopausal women with type 2 diabetes mellitus as an early process of diabetes-associated bone alterations: a cross-sectional study. BMC Endocr Disord. 2017; https://doi.org/10. 1186/s12902-017-0224-0.

36. Armstrong ME, Cairns BJ, Banks E, Green J, Reeves GK, Beral V. Different effects of age, adiposity and physical activity on the risk of ankle, wrist and hip fractures in postmenopausal women. Bone. 2012:50:1394-400.

37. De Laet C, Kanis JA, Oden A, et al. Body mass index as a predictor of fracture risk: a meta-analysis. Osteoporos Int. 2005;16:1330-8.

38. Prieto-Alhambra D, Premaor MO, Fina Aviles F, et al. The association between fracture and obesity is site-dependent: a population-based study in postmenopausal women. J Bone Miner Res. 2012;27:294-300.

39. Colaianni G, Brunetti G, Faienza MF, Colucci S, Grano M. Osteoporosis and obesity: role of Wnt pathway in human and murine models. World J Orthop. 2014:5:242-6.

40. Isaia GC, D'Amelio P, Di Bella S, Tamone C. Is leptin the link between fat and bone mass? J Endocrinol Invest. 2005;28Suppl 10:61-5

41. Kim JH, Choi HJ, Ku EJ, et al. Trabecular bone score as an indicator for skeletal deterioration in diabetes. J ClinEndocrinol Metab. 2015; 100:475-82.

42. Xu J, Yue F, Wang J, Chen L, Qi W. High glucose inhibits receptor activator of nuclear factor-kB ligand-induced osteoclast differentiation via downregulation of v-ATPase V0 subunit $\mathrm{d} 2$ and dendritic cell-specific transmembrane protein. Mol Med Rep. 2015;11:865-70.

43. Christman MA, Goetz DJ, Dickerson E, et al. Wnt5a is expressed in murine and human atherosclerotic lesions. Am J Physiol Heart Circ Physiol. 2008; 294:H2864-70

44. Gennari L, Merlotti D, Valenti R, et al. Circulating sclerostin levels and bone turnover in type 1 and type 2 diabetes. J Clin Endocrinol Metab. 2012 https://doi.org/10.1210/jc.2011-2958.

45. Gaudio A, Privitera F, Battaglia K, et al. Sclerostin levels associated with inhibition of the Wnt/ß-catenin signaling and reduced bone turnover in type 2 diabetes mellitus. J Clin Endocrinol Metab. 2012; https://doi.org/10. 1210/jc.2012-1901.

46. Napoli N, Strollo R, Defeudis G, et al. Serum Sclerostin and Bone Turnover in Latent Autoimmune Diabetes in Adults. J Clin Endocrinol Metab. 2018; https://doi.org/10.1210/jc.2017-02274.

47. Hygum K, Starup-Linde J, Harsløf T, Vestergaard P, Langdahl BL. MECHANISMS IN ENDOCRINOLOGY: Diabetes mellitus, a state of low bone turnover- a systematic review and meta-analysis. Eur J Endocrinol. 2017; https://doi. org/10.1530/EJE-16-0652.

48. Kalem MN, Kalem Z, Akgun N, Bakırarar B. The relationship between postmenopausal women's sclerostin levels and their bone density, age, body mass index, hormonal status, and smoking and consumption of coffee and dairy products. Arch Gynecol Obstet. 2017; https://doi.org/ 10.1007/s00404-017-4288-x.

49. Lappin DF, Eapen B, Robertson D, Young J, Hodge PJ. Markers of bone destruction and formation and periodontitis in type 1 diabetes mellitus. J Clin Periodontol. 2009; https://doi.org/10.1111/j.1600-051X.2009.01440.x

50. Galluzzi F, Stagi S, Salti R, et al. Osteoprotegerin serum levels in children with type 1 diabetes: a potential modulating role in bone status. Eur $J$ Endocrinol. 2005; https://doi.org/10.1530/eje.1.02052.
51. Abd El Dayem SM, El-Shehaby AM, Abd El Gafar A, Fawzy A, Salama H. Bone density, body composition, and markers of bone remodeling in type 1 diabetic patients. Scand J Clin Lab Invest. 2011; https://doi.org/ 10.3109/00365513.2011.573574.

52. D'Amelio P, Grimaldi A, Di Bella S, et al. Estrogen deficiency increases osteoclastogenesis up-regulating T cells activity: a key mechanism in osteoporosis. Bone. 2008;43:92-100
Ready to submit your research? Choose BMC and benefit from:

- fast, convenient online submission

- thorough peer review by experienced researchers in your field

- rapid publication on acceptance

- support for research data, including large and complex data types

- gold Open Access which fosters wider collaboration and increased citations

- maximum visibility for your research: over $100 \mathrm{M}$ website views per year

At BMC, research is always in progress.

Learn more biomedcentral.com/submissions 